\title{
Resposta inflamatória peritoneal de asininos (Equus asinus) submetidos à ovariectomia por laparotomia e laparoscopia
}

\author{
[Peritoneal inflammatory response of the donkeys (Equus asinus) submitted ovariectomy by \\ laparotomy and laparoscopy]
}

\author{
I.O. Barros ${ }^{1}$, N.B.S. Fonseca ${ }^{2}$, T.L. Nunes ${ }^{2}$, J.D. Spagnolo ${ }^{2}$, J.P.A. Santos ${ }^{4}$, A.S. Neto ${ }^{2}$, M.G.C. Oliveira ${ }^{2}$, \\ A.F.S. Nogueira ${ }^{4}$, R.S. Sousa ${ }^{3}$, L.C.L.C. Silva ${ }^{3}$, R.A. Barrêto Júnior ${ }^{2}$ \\ ${ }^{1}$ Universidade Federal da Paraíba - Areia, PB \\ ${ }^{2}$ Universidade Federal Rural do Semiárido - Mossoró, RN \\ ${ }^{3}$ Universidade de São Paulo - São Paulo, SP \\ ${ }^{4}$ Universidade Federal do Piauí - Bom Jesus, PI
}

\begin{abstract}
RESUMO
Objetivou-se avaliar resposta inflamatória e concentrações de proteínas em líquido peritonealde asininas submetidas à ovariectomia por laparotomia e laparoscopia. Foram utilizadas 18 fêmeas adultas, pesando em média $100 \mathrm{~kg}$, as quais foram divididas em dois grupos, de nove animais cada: o grupo I, em que foram ovariectomizadas por laparotomia, e o grupo II por laparoscopia. Após as cirurgias, em ambos os grupos foram avaliadas as seguintes variáveis no líquido peritoneal: $\mathrm{pH}$, densidade, número de hemácias, leucócitos e proteínas de fase aguda (fibrinogênio, haptoglobina, albumina, antitripsina, alfa-1 glicoproteína ácida, ceruloplasmina, transferrina, imunoglobulinas A e G). Todas as variáveis foram analisadas antes das cirurgias, 12, 24, 48, 72 horas, oito e 16 dias após os procedimentos cirúrgicos. O número de hemácias e leucócitos aumentou 24 horas depois das cirurgias nos dois grupos. Haptoglobina, alfa-1 glicoproteína ácida,albumina, transferrina, gamaglobulinas A, G e proteínas totais aumentaram nos dois grupos. As concentrações de ceruloplasmina não variaram enquanto a antitripsina não foi detectada no líquido peritoneal de asininos. Foi identificada uma proteína com23.000kD, que não tem denominação nem descrição no líquido peritoneal de asininos.
\end{abstract}

Palavras-chave: trauma, inflamação, haptoglobina

\begin{abstract}
The aim of this study was to evaluate the inflammatory response and protein concentrations in the peritoneal fluid of donkeys submitted to laparotomy and laparoscopic ovariectomy. Eighteen adult females, weighing on average 100kg, were divided into two groups, of 09 animals each, where in group I, they were ovariectomized by laparotomy and group II by laparoscopy. Following the surgeries, the following variables were evaluated in the peritoneal fluid: $\mathrm{pH}$, density, number of red cells, leukocytes and acute phase proteins (fibrinogen, haptoglobin, albumin, antitrypsin, alpha-1 acid glycoprotein, ceruloplasmin, transferrin, Immunoglobulins $A$ and $G)$. All variables were analyzed before the surgeries, 12, 24, 48, 72 hours, 8 and 16 days after the surgical procedures. The number of red cells and leukocytes increased 24 hours after the surgeries in both groups. Haptoglobin, alpha-1 acid glycoprotein, albumin, transferrin, gammaglobulins $A$ and $G$, and total proteins increased in both groups. Concentrations of ceruloplasmin did not change while antitrypsin was not detected in the asinine peritoneal fluid. A protein of 23,000kD, which has no name or description in the peritoneal liquid of donkeys, has been identified.
\end{abstract}

Keywords: trauma, inflammation, haptoglobin

Recebido em 24 de outubro de 2016

Aceito em 13 de julho de 2017

E-mail: doutorabella@hotmail.com 


\section{INTRODUÇÃO}

Os jumentos sempre acompanharam as populações mais pobres, sendo usados principalmente para transporte de carga e tração (Polidori e Vincenzetti, 2012). Atualmente, são bastante utilizados para produção de muares, atividades de lazer, turismo rural, terapia (French, 1997; The States Food..., 2015) e também para a produção de leite e derivados (Barlowskaet al., 2011). Por serem considerados rústicos e resistentes, a saúde e o bem-estar desses animais são negligenciados e, assim, são constantemente expostos a agentes infecciosos, parasitários, que podem causar diminuição da capacidade de trabalho e até óbitos (Regan et al., 2014; Stringer, 2014).

Várias são as injúrias inflamatórias, que podem desencadear dor e sofrimento aos asininos. De acordo com Pessoa et al. (2014), feridas traumáticas, fraturas em membros, problemas odontológicos e gastrointestinais são as afecções mais comuns em animais do semiárido brasileiro. Dessa forma, monitorar e diagnosticar essas enfermidades torna-se um desafio para o clínico, tendo em vista que os sinais clínicos nem sempre se manifestam de forma clara, já que pouco se sabe sobre a resposta inflamatória aguda nesses animais.

Uma das formas propostas recentemente é a utilização de proteínas de fase aguda, que são substâncias produzidas no fígado e liberadas em resposta à infecção e lesão tecidual (Jacobsen e Andersen, 2007). Segundo Jacobsen e Andersen (2007), as determinações locais dos níveis de proteínas de fase aguda são ferramentas importantes para determinar informações inflamatórias e infecciosas de órgão específico e, assim, melhorara precisão nos diagnósticos.

Nesse contexto, avaliação do líquido peritoneal tem sido cada vez mais preconizada, principalmente para fornecer informações que possam ser utilizadas para estabelecer diagnóstico, terapêutica clínica ou cirúrgica e prognóstico de algumas enfermidades (Thomassian, 2005) e também em situações em que outros exames se mostrarem inconclusivos (Macoris, 1995).

Marcadores inflamatórios, como proteínas de fase aguda, são reflexos da intensidade dos traumascirúrgicos e podem ser utilizados para avaliar as injúrias provocadas por diferentes técnicas cirúrgicas (Di Filippoet al., 2014). Em asininos, não há relatos sobre as proteínas de fase aguda presentes no líquido peritoneal, em especial quando submetidos à ovariectomia. $\mathrm{O}$ objetivo do trabalho é descrever e comparara resposta inflamatória e as proteínas de fase aguda presentes no líquido peritoneal de asininas submetidas à ovariectomia por laparotomia e laparoscopia.

\section{MATERIAL E MÉTODOS}

O presente trabalho foi aprovado pelo Comitê de Ética da Universidade Federal Rural do Semiárido (Ufersa), sob número 23091.000415/2014-11.Foram utilizados 18 asininos, fêmeas, pesando, em média, $102,75 \pm 15,04 \mathrm{~kg}$, com idade de $4,4 \pm 2,8$ anos. Todos os animais foramsubmetidos a exames clínicos, hemogramas, parasitológicos, exames para diagnóstico de anemia infecciosa equina e também foram desverminados $\left(7,5 \mathrm{mg} \cdot \mathrm{kg}^{-1}\right.$, Fenzol Pasta ${ }^{\circledR}$, Agener União, Brasil). Passaram por jejum sólido de 48 horas para concentrado, 24 horas para volumoso e 12 horas de água.

Os animais foram divididos aleatoriamente em dois grupos, com nove animais cada, em que os do grupo I (GI) foram submetidos à cirurgia por laparotomia bilateral do flanco e os do grupo II (GII) à cirurgia por videolaparoscopia. Os dois grupos foram submetidos ao mesmo protocolo de antissepsia, anestesia e de pós-operatório. Ambos os grupos foram mantidos em posições quadrupedais em tronco de contenção, quando foram realizadas tricotomias em ambos os flancos e antissepsia com iodopovidona degermante (Riodeine ${ }^{\circledR}$, Rioquímica, Brasil) e álcool 70\% (Rialcool 70 ${ }^{\circledR}$, Rioquímica, Brasil).

Após cateterização de ambas as veias jugulares, para um melhor controle da infusão dos fármacos,os grupos receberam o mesmo protocolo anestésico. Cada animal foi sedado com cloridrato de detomidina (Dormiun $\mathrm{V}^{\circledR}$, Agener União, Brasil) e sulfato de morfina (Dimorf $^{\circledR}$, Cristália, Brasil), recebendo bolus inicial de $0,02 \mathrm{mg} / \mathrm{kg}^{-1}$ e $0,2 \mathrm{mg} / \mathrm{kg}^{-1}$, respectivamente, endovenoso. Imediatamente após sedação, iniciou-se infusão contínua detomidina (Dormiun $\mathrm{V}^{\circledR}$, Agener União, Brasil) 
na velocidade de $0,02 \mathrm{mg} / \mathrm{kg} / \mathrm{h}^{-1}$ e morfina (Dimorf $^{\circledR}$, Cristália) $0,07 \mathrm{mg} / \mathrm{kg} / \mathrm{h}^{-1}$, em bomba de infusão programada (St680, Samtronic ${ }^{\circledR}$; LF Inject $^{\circledR}$, Brasil, respectivamente). Foram administrados $4 \mathrm{mg} / \mathrm{kg}^{-1}$ de lidocaína (Xylestesin $2 \%{ }^{\circledR}$, Cristália, Brasil), distribuídos nas linhas de incisões e nos pedículos ovarianos.

No grupo I, três minutos após anestesia local, foi realizada incisão de aproximadamente $10 \mathrm{~cm}$ em ambos os flancos, seguida da divulsão dos músculos oblíquo abdominal externo, interno e transverso do abdômen. Após ruptura do peritônio, conseguiu-se acesso à cavidade abdominal para identificação do ovário, realizouse anestesia dos pedículos ovarianos com lidocaína (Xylestesin $2 \%{ }^{\circledR}$, Cristália, Brasil). Posteriormente, foi feita homeostasia com auxílio de pinça hemostática e transfixação e ligadura do pedículo ovariano com fio categute número 0 (Catgut ${ }^{\circledR}$, Shalon, Brasil) e posterior secção. O peritônio e a musculatura abdominal foram suturados em padrão Sultan com fio absorvível categute 0 (Catgut ${ }^{\circledR}$, Shalon, Brasil). A pele foi suturada com fio mononáilon 0(Nylon ${ }^{\circledR}$, Shalon, Brasil) em padrão simples separado.

No grupo II, após anestesia, dois portais foram colocados no flanco. O primeiro (P1) sobre o último espaço intercostal, $5 \mathrm{~cm}$ ventral para o processo transverso vertebral, para a colocação do laparoscópio acoplado a uma fonte de luz alógena (Ferrari Medical ${ }^{\circledR}$, Brasil) e videocâmara (Pop Cam II ${ }^{\circledR}$, Asap, Ferrari Medical, Brasil). Após a criação de um pneumoperitônio de $08 \mathrm{mmHg}$ com gás carbônico, o portal instrumento $(\mathrm{P} 2)$ foi colocado no centro da fossa paralombar, evitando a punção do baço. Um afastador de circuito laparoscópico foi introduzido para segurar o pedículo ovariano. A incisão de flanco foi, então, ampliada, permitindo retirar ovário externamente ao abdômen, seguido de ligadura do pedículo com categute 0 (Catgut ${ }^{\circledR}$, Shalon, Brasil) e ressecção ovariana. Ao término do procedimento cirúrgico, o pneumoperitônio foi desfeito eos instrumentosforam removidos. Os músculos em P1 e P2 foram fechados em sutura Sultan usando categute 0 (Catgut ${ }^{\circledR}$, Shalon, Brasil). As incisões na pele em P1 e P2 foram fechadas em sutura simples separada, usando fio mononáilon 0 (Nylon ${ }^{\circledR}$, Shalon, Brasil).
O pós-operatório consistiu de limpeza diária da ferida cirúrgica, com água potável, sabão neutro, solução fisiológica $0,9 \%$ (Fisiológico ${ }^{\circledR}$, Eurofarma, Brasil) e aplicação de spraycicatrizante repelente (Aeorcid $\AA$, Agener União, Brasil) ao redor da ferida até retirada dos pontos, que foram realizados 12 dias póscirurgias. A antibioticoterapia utilizada foi associação entre penicilina procaína, potássica e estreptomicina (Agrosil@, Vansi, Brasil), na dose de $22.000 \mathrm{UI} / \mathrm{kg}^{-1}$, via intramuscular, a cada 48 horas, totalizando três aplicações. Concomitantemente, foi utilizado dipirona sódica (D-500® Fort Dodge, Brasil), $25 \mathrm{mg} / \mathrm{kg}^{-1}$, endovenoso, a cada 24 horas, durante cinco dias. Caso o animal manifestasse sinais clínicos evidentes de dor, seria aplicado cloridrato de tramadol (Tramadol ${ }^{\circledR}$, Teuto, Brasil), $2 \mathrm{mg} / \mathrm{kg}^{-1}$, endovenoso, como forma de resgate. Todos os animais receberam soro antitetânico (Vencosat ${ }^{\circledR}$, Vencofarma, Brasil), via subcutânea (5.000UI/animal), após cirurgia.

Para coleta do líquido peritoneal, cada animal de ambos os grupos foi contido em tronco e mantido em posição quadrupedal. Foi realizada ampla tricotomia da região xifoide até cicatriz umbilical. A coleta foi realizada na porção mais ventral do abdômen, com auxílio de agulha 40x12 introduzida lentamente na pele, em inclinação próxima a $90^{\circ}$, na região da linha média, até que o fluido fosse obtido, como descreveramLouro et al.(2006). O líquido foi coletado antes dos procedimentos cirúrgicos (M0), 12 (M12), 24 (M24), 48 (M48), 72 (M72) horas e oito (M8D), 16 (M16D) dias. As amostras foram coletadas em tubos com e sem EDTA.

Dos frascos coletados com EDTA foram realizadas as contagens de hemácias e leucócitos em câmara de Neubauer e a leitura manual. Para análise citológica diferencial, parte da amostra foi centrifugada a $1500 \mathrm{rpm}$ por cinco minutos. Foram realizados esfregaços com o sedimento, corados pelo método panótico (Panótico Rápido ${ }^{\circledR}$, Renylab, Brasil). A contagem diferencial foi realizada para um total de 100 leucócitos e células mesoteliais em microscópio óptico comum, em objetiva de 100x.

$\mathrm{O} \mathrm{pH}$ e a densidade foram mensurados pelo método de química seca em tiras reagentes (UriColor Check ${ }^{\circledR}$ - Wama Diagnóstica, Brasil). Já 
fibrinogênio foi realizado pelo método de precipitação a $56^{\circ} \mathrm{C}$ em tubos de microhematócrito, calculando-se a diferença entre a concentração de proteínas no plasma e no líquido peritoneal.

As concentrações de proteínas totais do soro foram obtidas pelo método do biureto, com auxílio de um conjunto de reagentes para diagnósticos $\left(\right.$ Labtest $^{\circledR}$, Sistema de Diagnósticos Ltda., Brasil) e leituras espectrofotométricas (E225-D, Labquest - CELM $^{\circledR}$, Brasil). Para fracionamento das proteínas, procedeu-se à eletroforese em gel de poliacrilamida, contendo dodecil sulfato de sódio (SDS-PAGE). Os pesos moleculares e as concentrações das frações proteicas foram determinados por densitometria computadorizada (Fotodyne ${ }^{\circledR}$, Fotodyne Inc, Estados Unidos). Para o cálculo do peso molecular, foram utilizados marcadores (Sigma Marker 6.500 - 200.000) de pesos moleculares de 200, 116, 97, 66, 55, 45, 36, 29, 24 e 20kDa, além das proteínas purificadas (Sigma Marker 6.500 - 200.000) albumina, al-antitripsina, haptoglobina, ceruloplasmina, transferrina e imunoglobulina $\mathrm{G}(\mathrm{Ig} G)$.

Os dados obtidos durante o período experimental foram analisados quanto a sua distribuição normal pela prova de Kolmogorov-Sminorv e avaliada a homogeneidade das variâncias. Os dados que obedeceram à distribuição normal foram submetidos à análise de variância (teste F), utilizando-se o procedimento PROC MIXED (Statitiscal..., 2012), para medidas repetidas no tempo, sendo estudado para cada variável o efeito de tratamento, o tempo e a interação entre tratamento e tempo. Foi considerado o critério de Akaike (AIC) para a escolha da melhor estrutura de covariância. A comparação das variáveis entre o momento basal e os demais momentos foi realizada pelo teste de média de Tukey.

Os dados do número de hemácias e leucócitos foram submetidos à transformação logarítmica, enquanto os dados de densidade, o número de neutrófilos e de fibrinogênio não obedeceram à distribuição normal, sendo utilizado o teste não paramétrico de Wilcoxon para a análise estatística. O grau de significância adotado foi de $\mathrm{P}<0,05$.

\section{RESULTADOS}

Os valores dos números de hemácias, leucócitos e pH obtidos das amostras de líquido peritoneal estão descritos na Tab. 1.

A contagem de hemácias não diferiu entre os grupos. No GI, ao se comparar com o momento antes da cirurgia, os números de eritrócitos aumentaram ao longo de todos os tempos de avaliação $(\mathrm{P}<0,05)$. No GII, também houve aumentos nas contagens de células vermelhas ao longo dos tempos, porém só até oito dias após a realização das cirurgias $(\mathrm{P}<0,05)$. O maior número de células obtidas das laparoscopias ocorreu depois de 24 horas (Tab. 1).

Os dois grupos apresentaram aumento no número total de leucócitos durante os tempos de avaliações, principalmente depois de 24 horas das realizações das ovariectomias $(\mathrm{P}<0,05)$. A contagem do número de neutrófilos não foi diferente quando comparados os grupos e ao longo dos tempos em cada grupo $(\mathrm{P}>0,672)$. A contagem dos demais tipos celulares também não foi diferente entre grupose ao longo dos momentos.

Houve mudanças em relação aos valores do $\mathrm{pH}$, quando comparados os grupos, 12 e 48 horas depois das cirurgias $(\mathrm{P}<0,05)$. Individualmente, os grupos não alteraram $\mathrm{pH}$ do líquido peritoneal durante todos os momentos de avaliação (Tab. 1). Os valores das medianas da densidade não diferiram entre os grupos (1.015), nem nos momentos de avaliação ( $\mathrm{P}>0,682)$.

As concentrações de proteínas totais e das proteínas de fase aguda (haptoglobina, ceruloplasmina, albumina, transferrina, alfa-1 glicoproteína ácida, imunoglobulinas A e G, fibrinogênio e P23000.kD) mensuradas no líquido peritoneal estão agrupadas na Tab. 2. 


\section{Barros et al.}

Tabela 1. Médias e desvios-padrão dos números de hemácias (x10\%/UL), leucócitos (x10³/UL) e pH do líquido peritoneal de asininas submetidas à ovariectomia por laparotomia (GI) ou por laparoscopia (GII)

\begin{tabular}{cccccccc}
\hline \multicolumn{7}{c}{ Momentos } \\
\hline Grupos & M0 & M12 & M24 & M48 & M72 & M8D & M16D \\
\hline GI & $2,85 \pm 3.06 \mathrm{~b}$ & $9,78 \pm 1,42 \mathrm{a}$ & $9,44 \pm 1,64 \mathrm{a}$ & $8,35 \pm 1,56 \mathrm{a}$ & $7,88 \pm 1,37 \mathrm{a}$ & $8,09 \pm 1,61 \mathrm{a}$ & $6,71 \pm 1,28 \mathrm{a}$ \\
GII & $4,11 \pm 2,60 \mathrm{c}$ & $9,17 \pm 1,99 \mathrm{ab}$ & $10,80 \pm 1,13 \mathrm{a}$ & $9,09 \pm 2,55 \mathrm{ab}$ & $8,28 \pm 2,21 \mathrm{ab}$ & $7,56 \pm 0,68 \mathrm{ab}$ & $6,55 \pm 1,50 \mathrm{bc}$ \\
\hline \multicolumn{7}{c}{ Leucócitos (x103/UL) } \\
\hline GI & $3,20 \pm 1,46 \mathrm{~b}$ & $7,57 \pm 1,17 \mathrm{a}$ & $8,22 \pm 0,80 \mathrm{a}$ & $7,54 \pm 0,97 \mathrm{a}$ & $7,17 \pm 0,94 \mathrm{a}$ & $7,62 \pm 0,98 \mathrm{a}$ & $6,89 \pm 0,91 \mathrm{a}$ \\
GII & $2,89 \pm 1,30 \mathrm{~b}$ & $7,29 \pm 1,34 \mathrm{a}$ & $8,19 \pm 0,42 \mathrm{a}$ & $7,44 \pm 0,62 \mathrm{a}$ & $7,75 \pm 0,77 \mathrm{a}$ & $7,75 \pm 0,64 \mathrm{a}$ & $6,73 \pm 1,03 \mathrm{a}$ \\
\hline & & \multicolumn{7}{c}{$\mathrm{pH}$} & \\
\hline GI & $7.62 \pm 0,20$ & $7,61 \pm 0,06 \mathrm{~A}$ & $7,53 \pm 0,27$ & $7,51 \pm 0,03 \mathrm{~B}$ & $7,50 \pm 0,06$ & $7,43 \pm 0,17$ & $7,51 \pm 0,12$ \\
GII & $7,53 \pm 0,09$ & $7,49 \pm 0,09 \mathrm{~B}$ & $7,54 \pm 0,16$ & $7,57 \pm 0,04 \mathrm{~A}$ & $7,51 \pm 0,09$ & $7,37 \pm 0,14$ & $7,41 \pm 0,13$ \\
\hline
\end{tabular}

Médias seguidas de letras diferentes minúsculas na linha diferem entre si pelo teste de Tukey $(\mathrm{P}<0,05)$.

Médias acompanhadas de letras diferentes maiúsculas na coluna diferem entre si, segundo análise de variância $(\mathrm{P}<0,05)$.

Tabela 2. Médias e desvios-padrão dos valores de proteínas totais (mg/dL), haptoglobina(mg/dL), ceruloplasmina $(\mathrm{mg} / \mathrm{dL})$, antitripsina $(\mathrm{mg} / \mathrm{dL})$, alfa-1-glicoproteína $(\mathrm{mg} / \mathrm{dL})$, imunoglobulinas A e G $(\mathrm{mg} / \mathrm{dL})$, fibrinogênio $(\mathrm{mg} / \mathrm{dL})$, albumina $(\mathrm{mg} / \mathrm{dL})$, transferrina $(\mathrm{mg} / \mathrm{dL})$ e P.23.000kD $(\mathrm{mg} / \mathrm{dL})$ do líquido peritoneal de asininas submetidas à ovariectomia por laparotomia (GI) ou por laparoscopia (GII)

\begin{tabular}{|c|c|c|c|c|c|c|c|}
\hline \multicolumn{8}{|c|}{ Momentos } \\
\hline $\begin{array}{c}\text { Grupo } \\
\text { s }\end{array}$ & M0 & M12 & M24 & M48 & M72 & M8D & M16D \\
\hline \multicolumn{8}{|c|}{ Proteínas totais (g/dL) } \\
\hline GI & $0,71 \pm 0,34 b$ & $3,90 \pm 1,26 a$ & $4,54 \pm 1,67 a$ & $3,31 \pm 1,97 a$ & $3,66 \pm 1,80 \mathrm{a}$ & $4,14 \pm 2,18 \mathrm{a}$ & $2,33 \pm 0,49 \mathrm{ab}$ \\
\hline GII & $0,74 \pm 0,50 \mathrm{c}$ & $4,06 \pm 1,57 \mathrm{ab}$ & $4,95 \pm 1,03 \mathrm{a}$ & $3,25 \pm 1,30 b$ & $3,26 \pm 0,77 \mathrm{ab}$ & $3,22 \pm 0,72 b$ & $2,71 \pm 1,01 b$ \\
\hline \multicolumn{8}{|c|}{ Haptoglobina (mg/dL) } \\
\hline GI & $0,43 \pm 0,29 \mathrm{c}$ & $7,61 \pm 3,04 a b c$ & $9,64 \pm 5,49 \mathrm{ab}$ & $5,82 \pm 4,00 \mathrm{abc}$ & $6,67 \pm 3,16 a b c$ & $13,09 \pm 10,86 a$ & $3,85 \pm 2,24 b c$ \\
\hline GII & $0,91 \pm 0,82 b$ & $9,19 \pm 3,64 \mathrm{a}$ & $11,25 \pm 5,35 \mathrm{a}$ & $9,32 \pm 5,06 a$ & $9,48 \pm 4,51 \mathrm{a}$ & $9,24 \pm 4,08 \mathrm{a}$ & $6,89 \pm 5,42 \mathrm{ab}$ \\
\hline \multicolumn{8}{|c|}{ Ceruloplasmina (mg/dL) } \\
\hline GI & $0,12 \pm 0,07$ & $0,22 \pm 0,19$ & $0,19 \pm 0,19$ & $0,29 \pm 0,18$ & $0,27 \pm 0,19$ & $0,24 \pm 0,12$ & $0,20 \pm 0,08$ \\
\hline GII & $0,20 \pm 0,14$ & $0,32 \pm 0,25$ & $0,17 \pm 0,17$ & $0,29 \pm 0,20$ & $0,23 \pm 0,15$ & $0,38 \pm 0,19$ & $0,22 \pm 0,09$ \\
\hline \multicolumn{8}{|c|}{ Albumina (mg/dL) } \\
\hline GI & $\begin{array}{c}45,78 \pm 21,72 \\
b\end{array}$ & $243,28 \pm 81,34 \mathrm{a}$ & $\begin{array}{c}260,16 \pm 90,18 \\
a\end{array}$ & $207,70 \pm 158,03 a$ & $\begin{array}{c}195,19 \pm 103,73 \\
\text { a }\end{array}$ & $\begin{array}{c}188,14 \pm 89,46 a \\
b\end{array}$ & $\begin{array}{c}140,82 \pm 55,00 a \\
b\end{array}$ \\
\hline GII & $\begin{array}{c}51,85 \pm 36,33 \\
\mathrm{~d}\end{array}$ & $\begin{array}{c}260,94 \pm 102,36 a \\
\text { b }\end{array}$ & $\begin{array}{c}281,56 \pm 52,99 \\
a\end{array}$ & $\begin{array}{c}192,99 \pm 81,76 a b \\
c\end{array}$ & $\begin{array}{c}176,20 \pm 44,86 b \\
c\end{array}$ & $\begin{array}{c}169,74 \pm 43,69 b \\
c\end{array}$ & $\begin{array}{c}150,29 \pm 53,24 \mathrm{c} \\
\mathrm{d}\end{array}$ \\
\hline \multicolumn{8}{|c|}{ Transferrina (mg/dL) } \\
\hline$\overline{\text { GI }}$ & $4,12 \pm 2,53 b$ & $23,26 \pm 9,52 a$ & $24,44 \pm 7,97 a$ & $13,62 \pm 2,84 \mathrm{ab}$ & $18,08 \pm 6,69 a$ & $17,86 \pm 9,01 \mathrm{a}$ & $13,75 \pm 5,64 \mathrm{ab}$ \\
\hline GII & $4,18 \pm 2,17 b$ & $26,78 \pm 10,51 \mathrm{a}$ & $27,79 \pm 12,71 \mathrm{a}$ & $18,63 \pm 7,71 \mathrm{a}$ & $22,09 \pm 4,90 \mathrm{a}$ & $15,51 \pm 7,10 \mathrm{ab}$ & $14,47 \pm 8,22 \mathrm{ab}$ \\
\hline \multicolumn{8}{|c|}{ Alfa-1 glicoproteína ácida (mg/dL) } \\
\hline GI & $0,12 \pm 0,13 b$ & $1,06 \pm 0,37 \mathrm{ab}$ & $1,06 \pm 0,56 a b$ & $0,75 \pm 0,50 \mathrm{ab}$ & $1,16 \pm 0,51 \mathrm{ab}$ & $1,45 \pm 1,13 \mathrm{a}$ & $0,86 \pm 0,72 \mathrm{ab}$ \\
\hline GII & $0,10 \pm 0,14 b$ & $0,91 \pm 0,37 \mathrm{ab}$ & $1,67 \pm 0,90 \mathrm{a}$ & $1,41 \pm 0,97 \mathrm{a}$ & $1,25 \pm 0,50 \mathrm{a}$ & $1,46 \pm 0,74 \mathrm{a}$ & $0,83 \pm 0,43 \mathrm{ab}$ \\
\hline \multicolumn{8}{|c|}{$\operatorname{IgA}(\mathrm{mg} / \mathrm{dL})$} \\
\hline GI & $0,39 \pm 0,19 b$ & $4,54 \pm 2,11 \mathrm{ab}$ & $8,48 \pm 6,24 a$ & $2,43 \pm 0,56 \mathrm{Bb}$ & $5,21 \pm 3,61 \mathrm{ab}$ & $5,25 \pm 2,38 \mathrm{ab}$ & $5,04 \pm 2,95 \mathrm{ab}$ \\
\hline GII & $0,47 \pm 0,36 b$ & $5,53 \pm 2,69 \mathrm{a}$ & $6,62 \pm 2,11 \mathrm{a}$ & $5,01 \pm 2,29 \mathrm{Aa}$ & $4,43 \pm 2,11 \mathrm{a}$ & $5,59 \pm 1,56 a$ & $3,99 \pm 2,20 \mathrm{a}$ \\
\hline \multicolumn{8}{|c|}{$\mathrm{IgG}(\mathrm{mg} / \mathrm{dL})$} \\
\hline GI & $16,76 \pm 8,99 b$ & $72,22 \pm 40,03 \mathrm{ab}$ & $\begin{array}{c}115,06 \pm 43,37 \\
\mathrm{a}\end{array}$ & $77,78 \pm 21,97 \mathrm{ab}$ & $104,72 \pm 59,00 \mathrm{a}$ & $118,49 \pm 61,09 a$ & $61,73 \pm 13,05 \mathrm{ab}$ \\
\hline GII & $\begin{array}{c}18,05 \pm 16,22 \\
\mathrm{c}\end{array}$ & $85,09 \pm 38,72 \mathrm{ab}$ & $\begin{array}{c}128,22 \pm 50,54 \\
a\end{array}$ & $80,21 \pm 35,73 a b$ & $82,31 \pm 28,94 \mathrm{ab}$ & $81,40 \pm 16,19 a b$ & $64,60 \pm 20,85 b c$ \\
\hline \multicolumn{8}{|c|}{ P.23.000kD (mg/dL) } \\
\hline GI & $1,08 \pm 0,85 b$ & $7,87 \pm 5,47 \mathrm{ab}$ & $6,48 \pm 4,20 \mathrm{ab}$ & $8,10 \pm 4,62 a b$ & $9,39 \pm 6,17 \mathrm{a}$ & $9,61 \pm 4,33 a$ & $7,14 \pm 4,09 \mathrm{ab}$ \\
\hline GII & $0,77 \pm 0,48 b$ & $8,05 \pm 4,06 \mathrm{a}$ & $9,98 \pm 1,39 a$ & $9,90 \pm 5,30 \mathrm{a}$ & $9,03 \pm 3,81 \mathrm{a}$ & $8,35 \pm 1,79 a$ & $8,33 \pm 3,98 \mathrm{a}$ \\
\hline
\end{tabular}

Médias seguidas de letras diferentes minúsculas na linha diferem entre si pelo teste de Tukey $(\mathrm{P}<0,05)$.

Médias acompanhadas de letras diferentes maiúsculas na coluna diferem entre si, segundo análise de variância $(\mathrm{P}<0,05)$. 
Para as fêmeas ovariectomizadas por laparotomia, houve aumentos nas concentrações de proteínas totais ao longo dos tempos avaliados, quando comparados com valores antes das realizações das cirurgias, com destaque nos momentos M24 e M8D ( $\mathrm{P}<0,05)$.

De todas as proteínas de fase aguda avaliadas, somente as concentrações de imunoglobulina A (IgA) apresentaram diferenças entre os grupos. Isso ocorreu apenas no momento M48 $(\mathrm{P}<0,05)$. A haptoglobina $(\mathrm{Hb})$, no GI, apresentou dois picos $(\mathrm{P}<0,05)$, primeiro com 24 horas e segundo com oito dias depois dosprocedimentos cirúrgicos. No GII, essa proteína $(\mathrm{Hb})$ apresentou aumentos $(\mathrm{P}<0,05)$ em todos os momentos (principalmente M24) depois das cirurgias, com exceção do M16D. A concentração de ceruloplasmina não diferiu entre grupos nem ao longo do tempo dentro de cada grupo $(\mathrm{P}>0,05)$.

No GI, as concentrações de albumina aumentaram até três dias depois que os animais foram operados, com grande elevação no M24 $(\mathrm{P}<0,05)$, enquanto no GII, o aumento foi significativo até oito dias depois, com pico máximo de elevação também no M24 $(\mathrm{P}<0,05)$.

A transferrina nos dois grupos demonstrou comportamento semelhante. No grupo I, aumentou em todos os tempos avaliados ( $\mathrm{P}<0,05)$, porém, nos tempos M48 e M16D, não variou. No GII, ela também se elevou em todos os momentos, com exceção no M8D e M16D. A alfa-1 glicoproteína ácida, no GI, aumentou somente oito dias depois. No GII, aumentou $(\mathrm{P}<0,05)$ com um, dois, três e até oito dias após realização das laparoscopias.

A IgA aumentou somente 24 e 48 horas nos animais do GI. Nos animais do GII, ela aumentou em todos os tempos depois da cirurgia, com destaque para M24 $(\mathrm{P}<0,05)$. A imunoglobulina $\mathrm{G}$ aumentou sua concentração, no GI, nos momentos M24, M72 e M8D $(\mathrm{P}<0,05)$. No GII, a IgG aumentou em todos os períodos de avaliação. As concentrações de fibrinogênio $(\mathrm{Fb})$ não foram diferentes entre os grupos. Também não apresentaram diferenças ao longo dos tempos $(\mathrm{P}>0,672)$ em cada grupo.

Por meio da eletroforese, foi identificada uma proteína, cujo peso era de $23.000 \mathrm{kD}$ nos dois grupos experimentais estudados. Quando comparados, os valores entre os grupos não diferiram. No GI,a concentração dessa proteína elevou-se no M24, M72 e M8D. Já no GII, ela aumentou em todos os momentos depois de realizadas cirurgias por laparoscopia.A antitripsina ou estava ausente ou não foi detectada no líquido peritoneal de asininos dos grupos estudados.

\section{DISCUSSÃO}

A técnica adotada para coleta do líquido peritoneal de asininos neste estudo demonstrou ser segura, barata, assim como relataram Louro et al. (2006), ao realizá-la também em asininos, e Neves et al. (2000), que realizaram em equinos. Algumas coletas foram tentadas com até oito horas depois das cirurgias, porém foram improdutivas, e o tempo foi excluído do delineamento experimental.

O volume coletado, em média, foi $25 \mathrm{~mL}$, bem inferior ao descrito por Parry e Browlow (1992), para equinos (50 a $60 \mathrm{~mL})$. A quantidade de líquido na cavidade abdominal pode ser influenciada pelo tipo de punção (agulha ou sonda), alimentação, posição, grau de repleção de alças e grau de desidratação. As alterações na coloração e no grau de turbidez podem ser influenciadas pela contaminação sanguínea durante punção, aumento de celularidade, elevação da taxa de proteínas totais, que podem ocorrer em processos inflamatórios e/ou infecciosos (Macoris, 1995; Faria et al.,1999). A cor amarelada e o grau de turbidez (ligeiramente turvo) encontrados neste estudo corroboram os descritos por Louro et al. (2006) para asininos, mas diferem do descrito por Thomassiam (2005) para cavalos.

O aumento de hemácias pode estar relacionado ao tipo de técnica utilizada para coleta do líquido peritoneal. Louro et al. (2006) também observaram aumento no número de hemácias peritoneais de asininos ao utilizarem agulha hipodérmica 40×12 para paracentese. Os maiores valores de hemácias GII podem ter sido ocasionados pela colocação e movimentação do instrumental laparoscópico utilizado.Se comparado com o pH de equinosdescrito por Mendes et al. (2000), o apresentado por asininos deste experimento, antes das cirurgias, encontrase dentro da normalidade. Porém, se comparados com os descritos por Silva (2005) para equinos 
saudáveis, os dados do $\mathrm{pH}$ peritoneal deste estudo estão baixos. Não foram encontrados relatos de valores de $\mathrm{pH}$ peritoneal de asininos.Os valores de densidade obtidos no estudo em asininos foram iguais aos descritos por Lhamas et al. (2015) em equinos de tração.

O aumento mais significativo do número de leucócitos ocorreu nos dois grupos 24 horas após as cirurgias. Apesar de não significativa, a contagem de neutrófilos também teve o mesmo pico de elevação. Os neutrófilos são as principais células constituintes do processo inflamatório inicial, atuam rápida e efetivamente como defesa celular primária contra microrganismos, com sua intensa atividade fagocitária e enzimática, e possuem também efeito quimiotático sobre os monócitos (Di Filippo, 2009). As duas abordagens cirúrgicas desencadearam processo inflamatório. Em todos os momentos avaliados de ambos os grupos, os valores de leucócitos ficaram abaixo do descrito para asininos (Louro et al., 2006). Nos animais ovariectomizados por laparoscopia, observou-se grande incômodo durante insuflação de $\mathrm{CO}_{2}$.

$\mathrm{Na}$ avaliação citológica peritoneal de asininos,espera-se, após injúria, que haja aumento no número de neutrófilos, seguido de eosinófilos, linfócitos e macrófagos (Louro et al., 2006), o que difere dos equinos, nos quais essa ordem muda para macrófagos, linfócitos e eosinófilos (Parry e Brownlow,1992), principalmente nos dois primeiros dias de injúrias. Neste estudo, ocorreu aumento numérico dos neutrófilos nos dois grupos, porém os outros tipos celulares não variaram.

$\mathrm{Na}$ avaliação proteica peritoneal, observou-se aumento nas concentrações de proteínas totais, principalmente com 24 horas, nos dois grupos. Isso ocorreu devido ao sequestro de proteínas em decorrência da exsudação inflamatória, estimulada pelo procedimento cirúrgico. A elevação das proteínas totais é um indicador importante de injúria inflamatória aguda de cavidade (Faria et al., 1999). Levando em consideração os dados descritos por Louro et al. (2006), o valor das proteínas totais em asininas ovariectomizadas voltouà normalidade somente depois de 16 dias.

Não foram identificadas na literatura proteínas de fase aguda em líquido peritoneal de asininos. A haptoglobina,no GII aumentou logo depois de 12 horas; posteriormente, os dois grupos elevaram os valores dessa. De acordo com Fagliari et al (2008), em líquido peritoneal de equinos, haptoglobina e ceruloplasmina são as primeiras proteínas de fase aguda que se elevam. Porém, em asininos, a ceruloplasmina não alterou em nenhum dos grupos e tempos estudados. Ao avaliarem perfil proteico peritoneal em equinos orquiectomizados, Di Filippo et al. (2014) também observaram elevações de haptoglobina no pós-cirúrgico imediato.

A albumina e a transferrina são proteínas de fase aguda negativas, pois elas diminuem suas concentrações ao longo do processo inflamatório (Murata et al., 2004). Entretanto, em asininos, elas se comportaram como proteínas positivas, pois as concentrações delas aumentaram ao longo dos tempos. A transferrina apresentou valores maiores nos animais operados pela laparoscopia. Comportamento semelhante foidescrito por Nogueira et al. (2014) no líquido peritoneal de equinos com obstrução intestinal.

Alfa-1 glicoproteína ácida comportou-se diferente em cada grupo. No GI, ela aumentou apenas depois de oito dias. No GII, ela elevou os níveis depois de 24 horas do procedimento cirúrgico, os quais permaneceram elevados também até oito dias. É considerada por Eckersall (2008) proteína moderada, com elevação lenta e duradoura, explicando, assim, os resultados obtidos neste estudo. Di Filippo et al (2011), ao avaliarem cavalos com obstrução intestinal, também descreveram aumento de alfa1 glicoproteína ácida, bem como haptoglobina, porém sem alterações de ceruloplasmina.

A imunoglobulina A aumentou em todos os tempos avaliados no GII. No GI, teve pico de aumento somente depois de 24 horas de cirurgia. A imunoglobulina $G$ também teve comportamento semelhante. Aumentos de gamaglobulinas, dentre elas IgA e IgG, podem estar relacionados à ação das interleucinas (principalmente a 6) na ativação inespecífica de células $\mathrm{B}$, resultando em anticorpos a partir de diferentes origens. O mesmo comportamento dessas gamaglobulinas foi descrito por Nogueira et al. (2014) em equinos.

O fibrinogênio, neste estudo, comportou-se de forma atípica, pois, em estimulações 
inflamatórias abdominais, espera-se que as concentrações dessa proteína se elevem. Porém, no líquido peritoneal de asininas ovariectomizadas por laparotomia ou laparoscopia, não houve mudanças nas concentrações dessa proteína de fase aguda. No líquido peritoneal de cavalos saudáveis, a concentração de fibrinogênio foi indetectável, de acordo com Silva (2005).

A proteína com $23.000 \mathrm{kD}$, identificada no líquido peritoneal de asininos, apresentou comportamento de proteína de fase aguda positiva, semelhante à fração alfa-2 globulina (Murata et al., 2004). O pico de concentração dessa proteína ocorreu no GI três dias depois de realizadas as cirurgias, e no GII, com dois dias. Aproteína de $24.000 \mathrm{kD}$, identificada no fluido abdominal de equinos por Nogueira et al. (2014), apresentou dinâmica semelhante. A dinâmica da antitripsina no líquido peritoneal de asininos foi igual à relatada em equinos por Nogueira et al. (2014).

\section{CONCLUSÕES}

$\mathrm{O}$ perfil inflamatório peritoneal e as concentrações de proteínas de fase aguda foram diferentes para duas técnicas adotadas, sendo observadas maiores respostas inflamatórias no líquido peritoneal de animais ovariectomizados por laparoscopia. As proteínas de fase aguda fibrinogênio e a ceruloplasmina apresentaram dinâmica diferente das descritas para equinos, além do aparecimento de uma proteína de fase aguda com peso molecular de $23.000 \mathrm{kDa}$ no líquido peritoneal ainda não descrita para asininos. Os resultados obtidos deste trabalho poderão servir de base para posteriores estudos com dinâmica inflamatória aguda de asininos.

\section{REFERÊNCIAS}

BARLOWSKA， J.; SZWAJKOWSKA， M.; LITWIŃCZUK, Z. et al. Nutritional value and technological suitability of milk from various animal species used for dairy production. Compr. Rev. Food. Sci. Food. Sci. Saf.,v.10, p.291-302, 2011.
DI FILIPPO, P.A. et al. Proteinograma sérico e do líquido peritoneal de equinos submetidos à orquiectomia. Cien. Rural, v.44, p.2221-2227, 2014.

DI FILIPPO, P.A.; SANTANA, A.E; COLETA, F.E.D. Avaliação clínica e eritroleucograma de equinos com cólica submetidos à laparotomia, sobreviventes e não sobreviventes. Cienc. Anim. Bras.,v.10, p.1246-1255, 2009.

DI FILIPPO, P.A.; NOGUEIRA, A. F.S.; ANAI, L. A. et al. Perfil eletroforético das proteínas séricas e do líquido peritoneal de equinos submetidos à obstrução experimental do duodeno, íleo e cólon maior. Cien. Anim.Bras.v.11, n.4, p.938-946, 2010.

ECKERSALL, P. D. Proteins, Proteomics and the Dysproteinemias. In: KANEKO, J. J.; HARVEY, J. W.; BRUSS M. L. Clinical Biochemistry of Domestic Animals, 6th ed. Burlington: Academic Press, 2008. p. 117-155.

FAGLIARI, J. J.; SILVA, S. L.; SILVA, P. C.; P.et al. Leucograma e teores plasmáticos de proteínas de fase aguda de equinos portadores de abdômen agudo e submetidos à laparotomia. Arq. Bras. Med. Vet. Zootec., Belo Horizonte, v. 60, n. 2, p. 322-328, 2008.

FARIA, E.P.; MARQUES JR. A.P.; ALVES, G.E.S. Características celulares e bioquímicas do líquido peritoneal de eqüinos submetidos à peritonite experimental. Arq. Bras. Vet. Zootec, v.51, p.335-344, 1999

FRENCH, J. Social behaviour. In: SVENDSEN E.D. (Ed.) The Professional handbook of the Donkey: compiled for the donkey sanctuary. 3.ed. London: Whittet Books, 1997. 400p.

JACOBSEN, S.; ANDERSEN, P.H. The acute phase protein serum amyloid A (SAA) as a marker of inflammation in horses. Equine Vet. Educ., v.19, p.38-46, 2007.

LHAMAS, C.L.; DUARTE, C.A.; LUBECK, I. et al. Influência do parasitismo intestinal sobre os parâmetros hematológicos e de líquido peritoneal em equinos de tração. Arq. Bras. Med. Vet. Zootec., v.67, p.381-390, 2015.

LOURO, M.F.C.; DIAS, R.V.C.; SOTOBLANCO, B. Avaliação do fluido peritoneal de asininos. Arq. Bras. Med. Vet. Zootec., v.58, p.955-958, 2006. 
MACORIS, D.G. Importância da avaliação do líquido peritoneal no diagnóstico e prognóstico da cólica. In: CICLO INTERNACIONAL DE CÓLICA EQÜINA, 2., 1995, Jaboticabal. Anais... Jaboticabal: FCAV-UNESP, 1995. p.2123.

MENDES, L.C.N.; PIERÓ, J.R.; MARQUES, L.C.; BORGES, A.S. Avaliação laboratorial do fluido peritoneal em modelos experimentais utilizados para indução de reação inflamatória intra-abdominal em equinos. Rev. Educ. Cont., v.3, p.21-27, 2000.

MURATA. H, SHIMADA. N, YOSHIOKA. M. Current research on acute phase proteins in veterinary diagnosis: an overview.Vet J., v.168, p.28-40, 2004.

NEVES, M.M. et al. Valores referenciais da análise do líquido peritoneal de equinos sadios. Cienc. Rural, v.30, p.809-811, 2000.

NOGUEIRA, A.F.S.; DI FILIPPO, P.A.; ANAI, L.A. et al. Establishment of peritoneal liquid electrophoretogram from healthy horses and horses submitted to experimentally induced intestinal obstruction.Arq. Bras. Med. Vet. Zootec., v.66, p.665-671, 2014.

PARRY, B.W.; BROWNLOW, M.A. Peritoneal fluid. In: COWELL R.L.; TYLER, R.D. Cytology and hematology of the horse. SI. Louis: Mosby, 1992. p.121-151.

PESSOA, A.F.A.; PESSOA, C.R.M.; MIRANDA NETO, E.G. et al. Doenças de asininos e muares no semiárido brasileiro. Pesqui. Vet. Bras., v.34, p.1210-1214, 2014.
PLIDORI, P.; VINCENZETTI, S. (2012). Protein Profile Characterization of Donkey Milk. Disponível em: http://cdn.intechopen.com/pdfswm/38824.pdf. Acesso em 21 jul. 2016.

REGAN, F. H.; HOCKENHULL, J.; PRITCHARD, J. C. et al. Behavioural repertoire of working donkeys and consistency of behaviour over time, as a preliminary step towards identifying pain-related behaviours. PLoS One., v.9, p.101877, 2014.

SILVA, G.F.K.T.Valores hematológicos, bioquímicos e exame do líquido peritoneal de equinos (Equus caballus, Linnaeus, 1758) durante síndrome cólica.2005. 81f. Dissertação (Mestrado em Medicina Veterinária) - Faculdade de Medicina Veterinária e Zootecnia, Universidade Estadual Paulista, Botucatu, SP.

STRINGER, A.P. Infectious diseases of working equids. Vet. Clin. Am. Equine Pract., v.30, p.695-718, 2014.

THE STATE of Food Insecurity in the World 2015. Meeting the 2015 international hunger targets: taking stock of uneven progress. Rome: FAO / IFAD, 2015. 56p. Available in: <http://www.fao.org/3/a-i4646e.pdf>. Accesseed in: 12 Jul. 2015.

THOMASSIAN, A. Enfermidades dos cavalos.4.ed. São Paulo: Varela, 2005. 335p. 